\title{
To towards real time insitu (noble) gas determination (or how mini- Ruedi Ruessel sniffs the world)
} UI GROUP ${ }^{1,2}$, MATTHIAS S. BRENNWALD ${ }^{1}$, YAMA
TOMONAGA ${ }^{1}$, RUEDI RÜSSEL $^{1}$, ROLF KIPFER $^{1,2}$

${ }^{1}$ Environmental Isotopes Group, Dept. of Water Resources and Drinking Water, Swiss Federal Institute of Aquatic Science and Technology (Eawag), 8600 Dübendorf, Switzerland,kipfer@eawag.ch

${ }^{2}$ Institute for Geochemistry and Petrology, ETH Zürich, 8092 Zürich, Switzerland

The currently available methods for determining (noble) gases in terrestrial fluids and water are laboratory-based, expensive and only allow limited number of samples to be analysed. Conventional techniques fall short in

- resolving (noble) gas patterns in space (high resolution gas mapping)

- determining the dynamics of (noble) gas / liquid exchange at short time scales being relevant for environmental processes (oxygen input during bank infiltration), or

- in analysing the gas evolution at particular sites (gas emanation at faults)

These experimental restrictions impede the powerful concepts of terrestrial noble gas geochemistry from being more widely adapted in environmental science and (tracer) hydrology.

To overcome these technical limitations, we developed a membrane inlet mass spectrometric system operating at gas / liquid equilibrium to analyse the gas composition in fluids and water [1]. Our new, second-generation system, 'MiniRuedi-Rüssel'(MRR, www.gasometrix.com, 1) is portable and self-contained ( $<40 \mathrm{~kg}$, operated via car batteries) and enables measuring concentrations of $\mathrm{He}, \mathrm{Ar}, \mathrm{Kr}, \mathrm{N}_{2}, \mathrm{O}_{2}, \mathrm{CH}_{4}$, $\mathrm{CO}_{2}$ and even $\mathrm{H}_{2}$ simultaneously and quasi-continuously (< 15 min.) in terrestrial fluids under field conditions.

Recently we applied MRR-systems to: determine the gas evolution in demonstration experiments for nuclear waste disposal [2], quantify denitrification and $\mathrm{N}_{2}$ production during bank infiltration [3], and analyse gas release during stimulated fracking experiments [4].

This presentation aims to describe the basic and robust technology of the MMR system, and discusses some of the most recent field applications.

[1] ES\&T 2016, 50, 13455-13463. [2] Appl. Geochem. 2019, 234-243. [3] ES\&T 2020, 54, 1562-1572. [4] Scientific reports in press. 